\title{
Research Paper: The Role of Difficulties in Emotion Regulation and Thought Control Strategies on Pornography Use
}

\author{
Mehdi Darvish Molla ${ }^{1 *}$, Mahmoud Shirazi ${ }^{1}$, Zahra Nikmanesh ${ }^{1}$
}

1. Department of Psychology, Faculty of Education and Psychology, University of Sistan and Baluchestan, Zahedan, Iran.

\begin{tabular}{|c|c|}
\hline $\begin{array}{l}\text { Use yur device to scan } \\
\text { and read the article online }\end{array}$ & Cttation: Darvish Molla, M., Shirazi, M., \& Nikmanesh, Z. (2018). The Role of Difficulties in Emotion Regula- \\
\hline 口6 & $\begin{array}{l}\text { tion and Thought Control Strategies on Pornography Use. Journal of Practice in Clinical Psychology, 6(2), 119-128. } \\
\text { https://doi.org/10.29252/NIRP.JPCP.6.2.119 }\end{array}$ \\
\hline 口투 & doi": https://doi.org/10.29252/NIRP.JPCP.6.2.119 \\
\hline
\end{tabular}

Article info:

Received: 07 Jul. 2017

Accepted: 16 Dec. 2017

Keywords:

Emotion regulation, Thought control, Pornography

\section{A B STRACT}

Objective: Due to easy accessibility to pornography for adolescents and youth, research on the use of pornography has proliferated in recent years. The aim of this study was to examine the role of difficulties in emotion regulation and thought control strategies on pornography use.

Methods: The population of this research included all students of the Sistan and Baluchestan University in southeastern Iran. A total of 395 students (193 men and 202 women), with a mean age of 22.35 years, were selected by multi-stage cluster sampling method. The participants completed the standardized measures of frequency of pornography use, difficulties in emotion regulation, and thought control strategies. Data were analyzed in SPSS (v. 22) software by using Pearson's correlation coefficient and Stepwise multiple regression.

Results: The results showed that $74 \%$ of men used pornography in the past 12 months; however, only $35 \%$ of women used pornography in the past 12 months. The results also revealed that pornography use was correlated with difficulties in emotion regulation and thought control strategies. Multiple regressions revealed that, in men, difficulties in emotion regulation $(\beta=0.27 ; \mathrm{P}<0.001)$ can positively predict pornography use and distraction $(\beta=-0.28 ; \mathrm{P}<0.001)$ can negatively predict pornography use. In addition, the results demonstrated that, in women, difficulties in emotion regulation $(\beta=0.30 ; \mathrm{P}<0.001)$ can positively predict pornography use and social control $(\beta=-0.18 ; \mathrm{P}<0.001)$ can negatively predict pornography use.

Conclusion: These findings indicated that difficulties in emotion regulation and thought control strategies (distraction and social control strategies) may successfully address the frequency of pornography use.



\section{Introduction}

$\mathrm{n}$ the current century, the media have progressed rapidly, and so have its power and influence. There are different types of me- dia that include various contents and themes. One of these themes and contents relates to sexual issues or the so-called pornography. Pornography refers to images and/or explicit descriptions of sexual acts, which create sexual thoughts, feelings, and behaviors (Hald \& Mala-

* Corresponding Author:

Mehdi Darvish Molla, MSc.

Address: Department of Psychology, Faculty of Education and Psychology, University of Sistan and Baluchestan, Zahedan, Iran.

Tel: +98 (936) 6527827

E-mail:darvishmolla@gmail.com 
muth, 2007; Kor, Fogel, Reid, \& Potenza, 2013; Reid, Li, Gilliland, Stein, \& Fong, 2011).

Studies conducted on the role of gender in the use of pornography have revealed that men, compared to women, are more likely to view pornography (Poulsen, Busby, \& Galovan, 2013; Willoughby, Carroll, Nelson, \& Padilla-Walker, 2014). Moreover, it has also been revealed that people under the age of 25 years are the greatest consumers of pornography (Træen, Spitznogle, $\&$ Beverfjord, 2004). In addition, men and women higher in psychopathy were more likely to use all forms of online pornographic content (Paul, 2009).

A number of studies have indicated that pornography can be used as a tool with a positive impact on people's lives so as to help people meet their sexual needs (Hald \& Malamuth, 2007; Paul \& Shim 2008). However, studies carried out to examine the effects of viewing pornography showed that using pornography was related to sexual risk behaviors (Harkness, Mullan, \& Blaszczynski, 2015) and sexual deviance (Kingston, Fedoroff, Firestone, Curry, \& Bradford, 2008).

Using pornography regularly several times per week (at least 11 hours a week) may become a compulsive and addictive pattern (Cooper, Putnam, Planchon, \& Boies, 1999; Wetterneck, Burgess, Short, Smith, \& Cervantes, 2012). The problematic and addictive use of pornography is defined as follows: failure to control pornography use and continuing its use despite its negative consequences and emotional distress related to the use of pornography such as guilt, shame, and regret (Grubbs, Stauner, Exline, Pargament, \& Lindberg, 2015).

Scientific evidence indicated that the problematic use of pornography was associated with more frequent consumption of alcohol (Svedin, Åkerman, \& Priebe, 2011). Many researchers found that pornography use has an addictive nature (Egan \& Parmar 2013; Grubbs, Volk, Exline, \& Pargament 2013). Furthermore, a number of researchers have considered the problematic use of pornography as a form of obsessive-compulsive disorder (Cooper, Delmonico, Griffin-Shelley, \& Mathy, 2004; Egan \& Parmar, 2013). To treat people who excessively used pornography, researchers applied the Acceptance and Commitment Therapy Model. They observed that the symptoms of obsessive-compulsive disorder and the use of pornography decreased in these people after the completion of this treatment course. (Twohig \& Crosby, 2010).

A limited number of studies have examined the motives for using pornography. For instance, Paul and
Shim (2009) demonstrated that one of the motives of using pornography was mood management. Moreover, researchers stated that some people applied the pornographic material to cope with distressing feelings and emotions (Cooper, et al. 2004). Furthermore, as mentioned earlier, emotion regulation is among the factors affecting pornography use.

Emotion regulation refers to the capacity to monitor, assess, understand, and change emotional reactions in a way that people are able to achieve their goals and reach adaptive functioning (Gratz \& Roemer, 2004). In contrast, the lack of emotion regulation indicates difficulties in experiencing and responding to emotional states, including difficulties in awareness, clarity, and acceptance of emotional responses (Gratz \& Roemer, 2004). The results of several studies have indicated that difficulty in emotion regulation was correlated with a wide range of disorders including eating disorders (Harrison, Sullivan, Tchanturia, \& Treasure, 2010), substance abuse (Tull, Weiss, Adams, \& Gratz, 2012), and alcoholism (Fox, Hong, \& Sinha, 2008).

Buckholdt et al. (2015) found that difficulty in emotion regulation was related to maladaptive behaviors (eating disorders, self-inflicted injury, and substance abuse). To perceive this relationship, the Experiential Avoidance Model can be taken into consideration. This model suggests that maladaptive behaviors (such as Internet addiction and binge eating) may be used to get rid of, manage, or avoid unwanted emotional experiences (Hayes, Wilson, Gifford, Follette, \& Strosahl, 1996; Kingston, Clarke, \& Remington, 2010). Additionally, the number of hours for which a person used pornography per week was related to the application of avoidance coping methods or experiential avoidance. Moreover, these people may use pornography as a method to escape from unpleasant and negative feelings (Cooper, et al., 1999).

Self-regulation is among the concepts that refer to emotion regulation and is defined as the ability to adjust thoughts, emotions, and behaviors according to internal and external needs (Kopp 1982). Hardy et al. (2013) found that self-regulation can prevent pornography use. Therefore, given that self-regulation, in addition to emotion regulation, includes thought adjustment, it can be mentioned that pornography use can be associated with emotion regulation and thought control.

Several studies examined thought control strategies and their impacts on behaviors. Overall, these studies demonstrated that the suppression of unwanted thoughts led to an increase in the frequency of that suppressed 
thought. In other words, as the suppression mechanism attempts to suppress unwanted thoughts, the frequency of these unwanted thoughts increases (Abramowitz, Tolin, \& Street, 2001). People used five general methods (distraction, worry, punishment, social control, and reappraisal) to control their intrusive thoughts (Wells \& Davies, 1994). Among these methods, worry and punishment were introduced as maladaptive strategies. In contrast, social control can be considered as an adaptive strategy (Wells \& Davies, 1994; Abramowitz, Whiteside, Kalsy, \& Tolin, 2003; Ellis \& Cropley, 2002; Allen, Krompinger, Mathes, Crosby, \& Elias, 2016; Amir, Cashman, \& Foa, 1997; Reynolds \& Wells, 1999).

Thought control strategies and difficulties in emotion regulation have been examined in various studies; however, the role of these factors in pornography use has not been studied. In addition, given the fact that users of sexually explicit media indicate more signs of physical and mental damage compared to those who do not apply these media and since using the sexually explicit media is particularly associated with symptoms of depression, an decrease in the number of days people have mental and physical health in the past month, and low quality of life (Weaver, et al., 2011) and considering that little research has been carried out to examine the predictors of pornography use, conducting more studies in this field seems essential. While most previous studies have investigated the effect of emotion on pornography use in clinical populations of adults, very little is known about the relationship between emotion, cognition, and pornography use in normal populations.

Therefore, the present study aimed to examine the role of difficulties in emotion regulation and thought control strategies in pornography use.

\section{Methods}

The statistical population of this cross-sectional study included all university students at the University of Sistan and Baluchestan in the academic year 2016-2017. The students were selected using the random sampling method (multistage cluster sampling method). In the first sampling step, three colleges (Humanities, Engineering and Basic Sciences) were randomly selected. Then, 6 classes were randomly chosen from every college. In the selected classes, the students were chosen randomly according to the class list. Finally, based on Morgan's table, a sample of 384 individuals was selected. A total of 420 questionnaires were distributed, of which 395 questionnaires were completely answered. The remaining 25 questionnaires were eliminated due to incompleteness.
Of the 395 respondents, 193(49.9\%) were men with a mean age of 22.21 years $(\mathrm{SD}=2.82)$ and $202(51.1 \%)$ were women with a mean age of 22.35 years $(\mathrm{SD}=3.35)$.

To analyze the data, the Pearson's correlation coefficient and multiple stepwise regression using SPSS v. 21 were applied. To observe ethical consideration, the main objective of the current study was explained to the participants before filling out the questionnaires. The subjects voluntarily answered the questions, and they were assured that their demographic information would remain confidential and that they could leave the research at any point of time.

Pornography Use. To assess the frequency of pornography use, the definition of pornography was initially provided to the participants. Afterwards, the following question was proposed: How often, on an average, did you watch pornographic videos, view pornographic photos, and read pornographic texts in the past 12 months? The subjects could choose one of the seven options to respond to the question: Not at all: 1 ; Once a year: 2 ; Once every 6 months: 3; Once a month: 4; Once a week: 5; Several times a week: 6; and Every day or Almost every day: 7. These questions have been used in several studies (Brown \& L'Engle 2009; Peter \& Valkenburg 2006). The Cronbach's alpha coefficient of these questions was 0.79 (Peter \& Valkenburg 2006). In the current study, the test-retest coefficient of these questions was 0.73 , and the overall Cronbach's alpha was 0.85 . Using the factor analysis, this model explained $71 \%$ of the variance, and the factor loading related to each question was 0.89 , 0.90 , and 0.72 for items related to videos, photos, and texts, respectively.

Difficulties in Emotion Regulation Scale included 36 items. The subscales of this scale are as follows: 1. Nonacceptance of emotional responses; 2. Difficulties in engaging in goal-directed behavior; 3. Impulse control difficulties; 4. Lack of emotional awareness; 5. Limited access to emotion regulation strategies; and 6. Lack of emotional clarity. The internal consistency of this scale was 0.93 , and its test-retest reliability was 0.88 (Gratz \& Roemer, 2004). Moreover, the Cronbach's alpha coefficient of the translated version of this scale ranged from 0.66 to 0.88 , and its test-retest reliability was reported between 0.79 and 0.91 (Khanzadeh, Saeediyan, Hosseinchari, \& Edrissi, 2012). In the present study, the Cronbach's alpha coefficient was 0.90 .

Thought Control Strategies Questionnaire. This questionnaire examined the individual differences in using various thought strategies and their relationship with 
emotional vulnerability. This questionnaire has five subscales including distraction (D), punishment (P), reappraisal $(\mathrm{R})$, worry $(\mathrm{W})$, and social control $(\mathrm{S})$. The Cronbach's alpha coefficient of its subscales ranged from 0.64 to 0.79 , and the test-retest correlations among its subscales ranged from 0.64 to 0.83 (Wells \& Davies, 1994). The internal consistency of the Persian version of Thought Control Strategies Questionnaire ranged from 0.64 to 0.74 , and the test-retest reliability of its subscales ranged from 0.50 to 0.60 (Fata, Moutabi, Moloudi, \& Ziayee, 2010). In the current study, the Cronbach's alpha coefficient of this scale was 0.73 .

\section{Results}

As expected, our results showed that men used pornography significantly more than women. A total of $74 \%$ of men reported that they have used pornography in the past 12 months compared to $35 \%$ of women who reportedly used pornography in the same period. Table 1 demonstrates the means and standard deviations re- lated to the variables under study. The obtained results from the independent t-test indicated that men significantly used more pornography and punishment strategy in comparison with women. The obtained results from the analyses of correlation of variables under study are separately presented for men and women in Table 2 . The results show that pornography use was significantly and positively related to the total score of difficulties in emotion regulation and subscales of non-acceptance, impulse control difficulties, and limited access to emotion regulation strategies for men and women. Furthermore, pornography use was significantly and positively related to difficulties in engaging in goal-directed behaviors among women and the lack of emotional awareness and lack of emotional clarity among men. Pornography use was significantly and negatively related to two thought control strategies: social control and distraction in women and distraction in men.

Table 3 presents the results of Stepwise multiple regression analysis conducted for the variables under study. In

Table 1. Descriptive statistics for both genders

\begin{tabular}{|c|c|c|c|}
\hline & Men's Mean (SD) & Women's Mean (SD) & T Value \\
\hline Pornography use & $8.72(5.22)$ & $4.47(2.58)$ & $10.18^{* * *}$ \\
\hline DERS total score & $97.76(20.27)$ & $95.63(19.45)$ & 1.07 \\
\hline DERS accept & $15.68(5.86)$ & $14.86(4.22)$ & 1.47 \\
\hline DERS goals & $15.08(4.06)$ & 15.04(3.79) & 0.08 \\
\hline DERS impulse & $16.84(5.21)$ & $16.06(5.00)$ & 1.51 \\
\hline DERS strategies & $20.26(6.31)$ & $20.34(6.78)$ & -0.12 \\
\hline DERS aware & $18.08(3.84)$ & $17.44(3.08)$ & 1.83 \\
\hline DERS clarity & $11.67(3.73)$ & $11.89(3.70)$ & -0.58 \\
\hline TCQ distraction & $15.12(3.54)$ & $15.71(3.54)$ & -1.65 \\
\hline TCQ worry & $12.07(3.39)$ & $11.26(3.48)$ & $2.34 * *$ \\
\hline TCQ punishment & $10.86(2.40)$ & $11.04(2.75)$ & -0.71 \\
\hline TCQ social control & $13.90(1.93)$ & $13.54(3.42)$ & 1.30 \\
\hline TCQ reappraisal & $14.94(2.79)$ & $14.74(3.28)$ & 0.65 \\
\hline
\end{tabular}

SD: Standard Deviation; DERS: Difficulties in Emotion Regulation Scale 


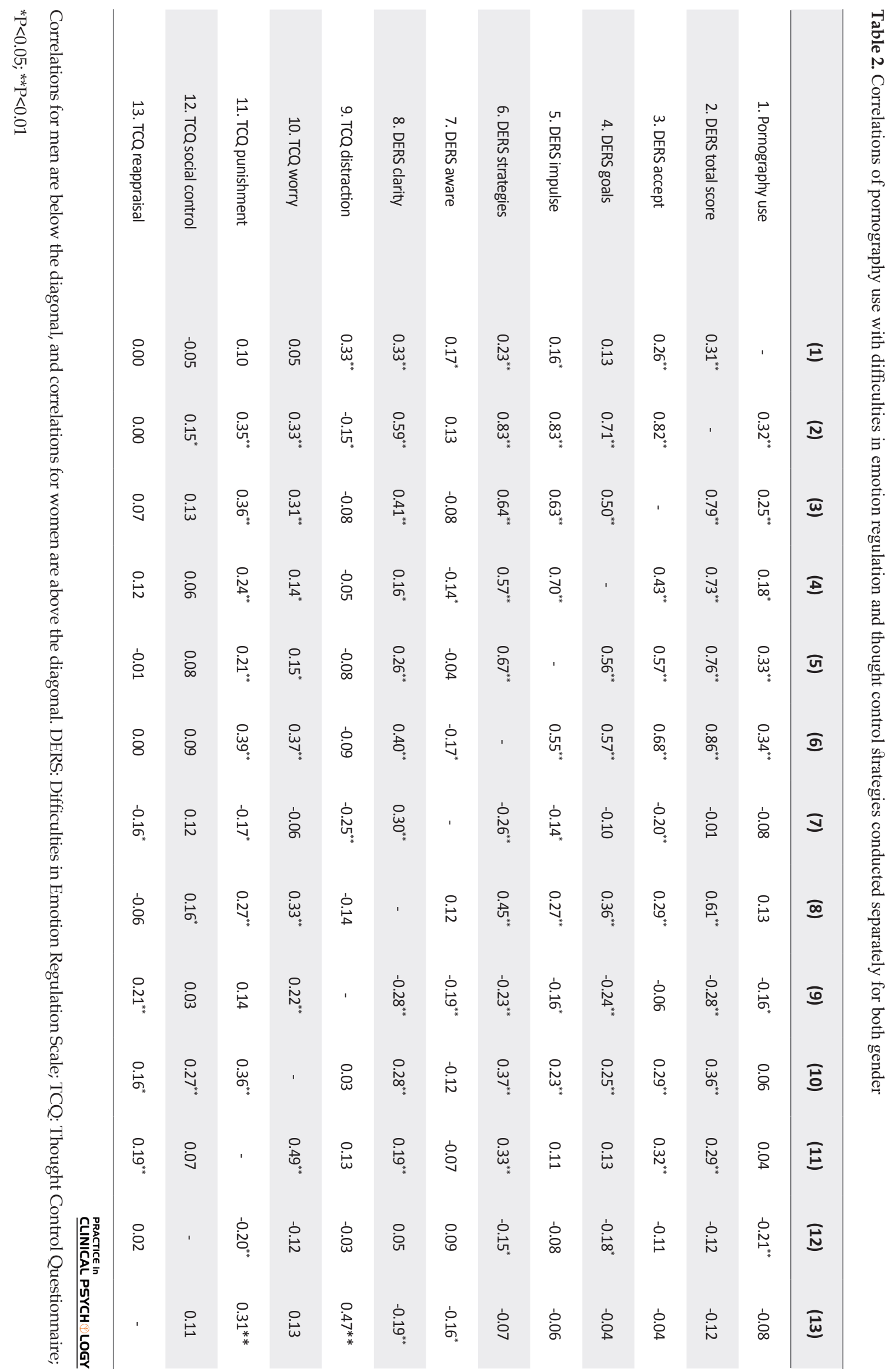


Table 3. Multiple regression analysis (with stepwise method) for pornography use

\begin{tabular}{|c|c|c|c|c|c|c|c|c|c|c|c|}
\hline \multicolumn{12}{|c|}{ Pornography Use } \\
\hline \multicolumn{6}{|c|}{ Men } & \multicolumn{6}{|c|}{ Women } \\
\hline Model & B & $\beta$ & $t$ & $f$ & $\Delta \mathbf{R}^{2}$ & Model & B & $\beta$ & $t$ & $f$ & $\Delta \mathbf{R}^{2}$ \\
\hline (1) & & & & $22.78^{* * *}$ & 0.10 & (1) & & & & $23.22^{* * *}$ & 0.10 \\
\hline $\begin{array}{l}\text { (Con- } \\
\text { stant) }\end{array}$ & 16.00 & & $10.22^{* * *}$ & & & (Constant) & 0.06 & & 0.07 & & \\
\hline $\begin{array}{l}\text { TCQ dis- } \\
\text { traction }\end{array}$ & -0.481 & -0.33 & $-4.77^{* * *}$ & & & DERS & 0.28 & 0.32 & $4.82^{* * *}$ & & \\
\hline (1) & & & & $20.38 * * *$ & 0.17 & (2) & & & & $15.49^{* * *}$ & 0.13 \\
\hline $\begin{array}{l}\text { (Con- } \\
\text { stant) }\end{array}$ & 8.25 & & $3.37^{* *}$ & & & (Constant) & 2.15 & & 1.78 & & \\
\hline $\begin{array}{l}\text { TCQ dis- } \\
\text { traction }\end{array}$ & -0.42 & -0.28 & $-4.28^{* * *}$ & & & DERS & 0.26 & 0.30 & $4.54^{* * *}$ & & \\
\hline DERS & 0.07 & 0.27 & $4.02^{* * *}$ & & & $\begin{array}{c}\text { TCQ social } \\
\text { control }\end{array}$ & -0.13 & -0.18 & $2.66^{* *}$ & & \\
\hline
\end{tabular}

DERS: Difficulties in Emotion Regulation Scale; TCQ: Thought Control Questionnaire

**P $<0.01 ;{ }^{* * * \mathrm{P}<0.00}$

the first step, difficulties in emotion regulation had a significant and positive relationship with pornography use, and it explained $10 \%$ of the variance in pornography use among women. However, distraction had a significant and negative relationship with pornography use, and it explained $10 \%$ of the variance in the pornography use among men. In the second step, difficulties in emotion regulation and distraction explained $17 \%$ of the variance in pornography use among men and $13 \%$ of the variance in pornography use among women.

The results indicated that, in men, difficulties in emotion regulation $(\beta=0.27 ; \mathrm{P}<0.001)$ can predict pornography use and that distraction $(\beta=-0.28 ; \mathrm{P}<0.001)$ can negatively predict pornography use. In addition, the results demonstrated that, in women, difficulties in emotion regulation $(\beta=0.30 ; \mathrm{P}<0.001)$ can predict pornography use and that social control $(\beta=-0.18 ; \mathrm{P}<0.001)$ can negatively predict pornography use.

\section{Discussion}

The present study sought to examine the role of difficulties in emotion regulation and thought control strategies in pornography use. Our results indicated that difficulty in emotion regulation, in both genders, was significantly and positively related to pornography use. Among the subscales of difficulties in emotion regulation, the lack of emotional clarity among men and difficulty in controlling impulsive behaviors among women had the greatest relationships with pornography use. The results of multiple regression analysis demonstrated the role of difficulties in emotion regulation in predicting pornography use, such that an increase in the level of difficulties in emotion regulation led to an increase in the possibility of pornography use.

These results were in line with the results obtained from previously conducted studies. Previous studies conducted to examine the correlation between negative emotions and pornography use indicated that some of the people under study used pornography as a method to adjust or avoid their emotions (Cooper, et al., 2004; Paul \& Shim, 2008). The findings of the current study revealed that some thought control strategies had negative correlations with pornography use; however, these strategies were different for men and women. In women, distraction and social control had negative relationships with pornography use and only social control had a negative power to predict pornography use. In men, distraction had a diverse relationship with pornography use and was able to predict it negatively.

The results of the current study were consistent with the results of previous studies; in many studies, the distraction and social control strategies were considered as effective and useful strategies (Abramowitz, et al., 2001; Ellis \& Cropley, 2002; Wells \& Davies, 1994). For instance, studies conducted on people with posttraumatic stress disorder and sleep disorder indicated that, among various thought control strategies, distraction and social control can improve these patients' conditions such that 
an increase in the use of these strategies reduced their problems in controlling their intrusive and unwanted thoughts (Reynolds \& Wells, 1999).

Therefore, difficulties in emotion regulation have been reported to be associated with eating disorders (Harrison, et al., 2010), alcoholism (Fox, et al., 2008), and substance abuse (Tull, et al., 2012); it was also related to pornography use. This can be explained by the fact that people with weak emotional regulation often attempt to escape from their emotions through eating more food, consuming more alcohol, and/or using more pornography. According to the Experiential Avoidance Model, the main reasons of such behaviors may be these people's severe emotional responses, weakness in enduring distress, and lack of emotion regulation skills when experiencing provocative and stimulating emotions. Moreover, based on this model, although applying such behaviors in the short time may reduce distress, chronic use of maladaptive behaviors used to get rid of negative emotions may have the opposite effects and may increase the distress (Hayes, et al., 1996; Kingston, et al., 2010). In this regard, given these results, it can be said that a vicious cycle emerges in people who use more pornography, such that they feel shame and regret (Grubbs, et al., 2015) and have negative emotions (Willoughby, et al., 2014) due to their high usage of pornography. Moreover, given their difficulties in emotion regulation, they may use more and more pornography to get rid of these emotions.

On the one hand, high pornography use may result in an obsessive-compulsive use of pornography (Cooper, et al., 2004). On the other hand, the problematic use of pornography and obsessive-compulsive disorder are correlated (Egan \& Parmar, 2013; Twohig \& Crosby, 2010). The use of strategies such as distraction (as an instance: doing something that I enjoy) and social control (as an instance: talking to a friend about the thought), which play a key role in improving patients with obsessivecompulsive disorder (Allen, et al., 2016; Amir, et al., 1997), can be effective in preventing the addiction to pornography and reducing pornography use. Finally, considering the direct relationship between pornography use and the use of avoidance coping methods (Wetterneck, et al., 2012) and since the Acceptance and Commitment Therapy, that is based on accepting emotions and thoughts (Hayes, et al., 1996), is effective in reducing pornography use (Twohig \& Crosby, 2010), it can be said that social control can be effective in reducing pornography use. Here, social control refers to the act in which a person discusses his/her thoughts and decreases the level of avoidance from thoughts and emotions (Reynolds \& Wells, 1999).
The limitations of this study are described as follows: all results obtained in the current study were gained through applying questionnaires; therefore, the results may be affected by biases that occur in the self-report research. Moreover, since this study was conducted in a society with religious tendencies, there is a possibility of bias in answering the questions related to pornography. Additionally, applying the cross-sectional design and choosing a particular group of people as subjects (university students) create some restrictions on generalizing the results of this study.

The present study indicated that pornography use was positively related to the level of difficulties in emotion regulation. Moreover, it was negatively correlated with distraction and social control. These findings can be applied to aid people who excessively use pornography to reduce the use of pornography. However, more studies should be conducted on the role of difficulties in emotion regulation and thought control strategies in the level of pornography use in order to use these results to treat people who use pornography in an addictive way. To this end, future studies should examine the relationship between pornography use, cognitive emotion regulation and depression in different cultural groups that may help to generalize the findings of this study.

\section{Acknowledgments}

The current study was extracted from Darvish Molla's MA thesis of General Psychology presented in Department of Psychology, Faculty of Education and Psychology, University of Sistan and Baluchestan. The authors appreciate the students who participated in this study. We acknowledge the financial support from the University of Sistan and Baluchestan.

\section{Conflict of Interest}

The authors declared no conflicts of interest. The authors' contribution is as follows: Project managers and designers of the research: Mehdi Darvishmolla; collaborated in analyzing data and writing the paper: Mahmoud Shirazi; collaborated in collecting data and prepared the literature review: Zahra Nikmanesh.

\section{References}

Abramowitz, J. S., Tolin, D. F., \& Street, G. P. (2001). Paradoxical effects of thought suppression: a meta-analysis of controlled studies. Clinical Psychology Review, 21(5), 683-703. doi: 10.1016/s0272-7358(00)00057-x 
Abramowitz, J. S., Whiteside, S., Kalsy, S. A., \& Tolin, D. F. (2003). Thought control strategies in obsessive-compulsive disorder: a replication and extension. Behaviour Research and Therapy, 41(5), 529-40. doi: 10.1016/s0005-7967(02)00026-8

Allen, K. J. D., Krompinger, J. W., Mathes, B. M., Crosby, J. M., \& Elias, J. A. (2016). Thought control strategies in patients with severe obsessive-compulsive disorder: Treatment effects and suicide risk. Journal of Obsessive-Compulsive and Related Disorders, 8, 31-7. doi: 10.1016/j.jocrd.2015.11.004

Amir, N., Cashman, L., \& Foa, E. B. (1997). Strategies of thought control in obsessive-compulsive disorder. Behaviour Research and Therapy, 35(8), 775. doi: 10.1016/s0005-7967(97)00030-2

Brown, J. D., \& L'Engle, K. L. (2009). X-rated: Sexual attitudes and behaviors associated with US early adolescents' exposure to sexually explicit media. Communication Research, 36(1), 12951. doi: $10.1177 / 0093650208326465$

Buckholdt, K. E., Parra, G. R., Anestis, M. D., Lavender, J. M. Jobe-Shields, L. E., Tull, M. T., et al. (2014). Emotion regulation difficulties and maladaptive behaviors: Examination of deliberate self-harm, disordered eating, and substance misuse in two samples. Cognitive Therapy and Research, 39(2), 140-52. doi: 10.1007/s10608-014-9655-3

Cooper, A., Delmonico, D. L., Griffin Shelley, E., \& Mathy, R. M. (2004). Online sexual activity: An examination of potentially problematic behaviors. Sexual Addiction \& Compulsivity, 11(3), 129-43. doi: 10.1080/10720160490882642

Cooper, A., Putnam, D. E., Planchon, L. A., \& Boies, S. C. (1999). Online sexual compulsivity: Getting tangled in the net. Sexual Addiction \& Compulsivity, 6(2), 79-104. doi: $10.1080 / 10720169908400182$

Egan, V., \& Parmar, R. (2013). Dirty habits? Online pornography use, personality, obsessionality, and compulsivity. Journal of Sex \& Marital Therapy, 39(5), 394-409. doi 10.1080/0092623x.2012.710182

Ellis, J., \& Cropley, M. (2002). An examination of thought control strategies employed by acute and chronic insomniacs. Sleep Medicine, 3(5), 393-400. doi: 10.1016/s1389-9457(02)00039-4

Fata, L., Moutabi, F., Moloudi, R., \& Ziayee, K. (2010). Psychometric properties of Persian version of thought control questionnaire and anxious thought inventory in Iranian students. Journal of Psychological Models and Methods, 1(1), 81-103.

Fox, H. C., Hong, K. A., \& Sinha, R. (2008). Difficulties in emotion regulation and impulse control in recently abstinent alcoholics compared with social drinkers. Addictive Behaviors, 33(2), 388-94. doi: 10.1016/j.addbeh.2007.10.002

Gratz, K. L., \& Roemer, L. (2004). Multidimensional assessment of emotion regulation and dysregulation: Development, factor structure, and initial validation of the difficulties in emotion regulation scale. Journal of Psychopathology and Behavioral Assessment, 26(1), 41-54. doi: 10.1023/b:jo ba.0000007455.08539.94

Grubbs, J. B., Stauner, N., Exline, J. J., Pargament, K. I., \& Lindberg, M. J. (2015). Perceived addiction to internet pornography and psychological distress: Examining relationships concurrently and over time. Psychology of Addictive Behaviors, 29(4), 1056-67. doi: 10.1037/adb0000114

Grubbs, J. B., Volk, F., Exline, J. J., \& Pargament, K. I. (2013). Internet pornography use: Perceived addiction, psy- chological distress, and the validation of a brief measure. Journal of Sex E Marital Therapy, 41(1), 83-106. doi: 10.1080/0092623x.2013.842192

Hald, G. M., \& Malamuth, N. M. (2007). Self-perceived effects of pornography consumption. Archives of Sexual Behavior, 37(4), 614-25. doi: 10.1007/s10508-007-9212-1

Hardy, S. A., Steelman, M. A., Coyne, S. M., \& Ridge, R. D. (2013). Adolescent religiousness as a protective factor against pornography use. Journal of Applied Developmental Psychology, 34(3), 131-9. doi: 10.1016/j.appdev.2012.12.002

Harkness, E. L., Mullan, B., \& Blaszczynski, A. (2015). Association Between pornography use and sexual risk behaviors in adult consumers: A systematic review. Cyberpsychology, Behavior, and Social Networking, 18(2), 59-71. doi: 10.1089/cyber. 2014.0343

Harrison, A., Sullivan, S., Tchanturia, K., \& Treasure, J. (2010). Emotional functioning in eating disorders: attentional bias, emotion recognition and emotion regulation. Psychological Medicine, 40(11), 1887-97. doi: 10.1017/s0033291710000036

Hayes, S. C., Wilson, K. G., Gifford, E. V., Follette, V. M., \& Strosahl, K. (1996). Experiential avoidance and behavioral disorders: A functional dimensional approach to diagnosis and treatment. Journal of Consulting and Clinical Psychology, 64(6), 1152-68. doi: 10.1037/0022-006x.64.6.1152

Khanzadeh, M., Saeediyan, M., Hosseinchari, M., \& Edrissi, F. (2012). Factor structure and psychometric properties of difficulties in emotional regulation scale. International Journal of Behavioral Sciences, 6(1), 87-96.

Kingston, D. A., Fedoroff, P., Firestone, P., Curry, S., \& Bradford J. M. (2008). Pornography use and sexual aggression: the impact of frequency and type of pornography use on recidivism among sexual offenders. Aggressive Behavior, 34(4), 341-51. doi: 10.1002/ab.20250

Kingston,J., Clarke, S., \& Remington, B. (2010). Experiential avoidance and problem behavior: A mediational Analysis. Behavior Modification, 34(2), 145-63. doi: 10.1177/0145445510362575

Kopp, C. B. (1982). Antecedents of self-regulation: A developmental perspective. Developmental Psychology, 18(2), 199-214. doi: 10.1037/0012-1649.18.2.199

Kor, A., Fogel, Y. A., Reid, R. C., \& Potenza, M. N. (2013). Should hypersexual disorder be classified as an addiction. Sexual Addiction \& Compulsivity, 20(1-2), 27-47. doi: 10.1080/10720162.2013.768132.

Paul, B. (2009). Predicting internet pornography use and arousal: the role of individual difference variables. Journal of Sex Research, 46(4), 344-57. doi: 10.1080/00224490902754152

Paul, B., \& Shim, J. W. (2008). Gender, sexual affect, and motivations for internet pornography use. International Journal of Sexual Health, 20(3), 187-99. doi: 10.1080/19317610802240154

Peter, J., \& Valkenburg, P. M. (2006). Adolescents' exposure to sexually explicit online material and recreational attitudes toward sex. Journal of Communication, 56(4), 639-60. doi 10.1111/j.1460-2466.2006.00313.x

Poulsen, F. O., Busby, D. M., \& Galovan, A. M. (2013). Pornography use: Who uses it and how it is associated with couple outcomes. Journal of Sex Research, 50(1), 72-83. doi: 10.1080/00224499.2011.648027 
Reid, R. C., Li, D. S., Gilliland, R., Stein, J. A., \& Fong, T. (2011). Reliability, validity, and psychometric development of the pornography consumption inventory in a sample of hypersexual men. Journal of Sex \& Marital Therapy, 37(5), 359-85. doi: 10.1080/0092623x.2011.607047

Reynolds, M., \& Wells, A. (1999). The Thought Control Questionnaire - psychometric properties in a clinical sample, and relationships with PTSD and depression. Psychological Medicine, 29(5), 1089-99. doi: 10.1017/s003329179900104x

Svedin, C. G., Åkerman, I., \& Priebe, G. (2011). Frequent users of pornograph: A population based epidemiological study of Swedish male adolescents. Journal of Adolescence, 34(4), 77988. doi: 10.1016/j.adolescence.2010.04.010

Træen, B., Spitznogle, K., \& Beverfjord, A. (2004). Attitudes and use of pornography in the Norwegian population 2002. Journal of Sex Research, 41(2), 193-200. doi:10.1080/00224490409552227

Tull, M. T., Weiss, N. H., Adams, C. E., \& Gratz, K. L. (2012). The contribution of emotion regulation difficulties to risky sexual behavior within a sample of patients in residential substance abuse treatment. Addictive Behaviors, 37(10), 1084-92. doi: 10.1016/j.addbeh.2012.05.001

Twohig, M. P., \& Crosby, J. M. (2010). Acceptance and commitment therapy as a treatment for problematic internet pornography viewing. Behavior Therapy, 41(3), 285-95. doi: 10.1016/j. beth.2009.06.002

Weaver, J. B., Weaver, S. S., Mays, D., Hopkins, G. L., Kannenberg, W., \& McBride, D. (2011). Mental- and physical- health indicators and sexually explicit media use behavior by adults. The Journal of Sexual Medicine, 8(3), 764-72. doi: 10.1111/j.17436109.2010.02030.x

Wells, A., \& Davies, M. I. (1994). The thought control questionnaire: A measure of individual differences in the control of unwanted thoughts. Behaviour Research and Therapy, 32(8), 871-8. doi: 10.1016/0005-7967(94)90168-6

Wetterneck, C. T., Burgess, A. J., Short, M. B., Smith, A. H., \& Cervantes, M. E. (2012). The role of sexual compulsivity, impulsivity, and experiential avoidance in internet pornography use. The Psychological Record, 62(1), 3-18. doi: 10.1007/ bf03395783

Willoughby, B. J., Carroll, J. S., Nelson, L. J., \& Padilla-Walker, L. M. (2014). Associations between relational sexual behaviour, pornography use, and pornography acceptance among US college students. Culture, Health $\mathcal{E}$ Sexuality, 16(9), 1052-69. doi: $10.1080 / 13691058.2014 .927075$ 
